\title{
Recent opioid use and fall-related injury among older patients with trauma
}

\author{
Raoul Daoust MD MSc, Jean Paquet PhD, Lynne Moore PhD, Marcel Émond MD MSc, Sophie Gosselin MD, \\ Gilles Lavigne DMD PhD, Manon Choinière PhD, Aline Boulanger MD, Jean-Marc Mac-Thiong MD, \\ Jean-Marc Chauny MD MSc
}

Cite as: CMAJ 2018 April 23;190:E500-6. doi: 10.1503/cmaj.171286

\begin{abstract}
BACKGROUND: Evidence for an association between opioid use and risk of falls or fractures in older adults is inconsistent. We examine the association between recent opioid use and the risk, as well as the clinical outcomes, of fall-related injuries in a large trauma population of older adults.
\end{abstract}

METHODS: In a retrospective, observational, multicentre cohort study conducted on registry data, we included all patients aged 65 years and older who were admitted (hospital stay $>2$ d) for injury in 57 trauma centres in the province of Quebec, Canada, between 2004 and 2014. We looked at opioid prescriptions filled in the 2 weeks preceding the trauma in patients who sustained a fall, compared with those who sustained an injury through another mechanism.

RESULTS: A total of 67929 patients were retained for analysis. Mean age was 80.9 ( \pm 8.0 ) years and $69 \%$ were women. The percentage of patients who had filled an opioid prescription in the 2 weeks preceding an injury was $4.9 \%$ (95\% confidence interval $[\mathrm{Cl}] 4.7 \%-5.1 \%$ ) for patients who had had a fall, compared with $1.5 \%$ (95\% Cl $1.2 \%-1.8 \%$ ) for those who had had an injury through another mechanism. After we controlled for confounding variables, patients who had filled an opioid prescription within 2 weeks before injury were 2.4 times more likely to have a fall rather than any other type of injury. For patients who had a fall-related injury, those who used opioids were at increased risk of in-hospital death (odds ratio 1.58; 95\% $\mathrm{Cl} 1.34-1.86$ ).

INTERPRETATION: Recent opioid use is associated with an increased risk of fall and an increased likelihood of death in older adults.

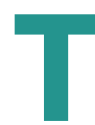

he rate of opioid prescription for pain treatment has been increasing rapidly in North America in the past 20 years. ${ }^{1,2}$ For example, between 2001 and 2010, the percentage of patients receiving an opioid prescription during an emergency department visit increased from $20.8 \%$ to $31 \%$, a relative increase of $49 \% .{ }^{1}$ Furthermore, the frequency of opioid prescription increases with age. ${ }^{3}$

Opioids are sometimes necessary to treat acute pain, but they can cause adverse effects, especially in the older population..$^{4-6}$ It has been found that drugs that affect the central nervous system (e.g., drugs that cause sedation and dizziness) can increase the risk of falling. ${ }^{7}$ Falls are frequent among people aged 65 years and older (28\%-35\% fall each year) $)^{8}$ and constitute a leading cause of injuries, hospital admissions and deaths among older people. ${ }^{9}$

Several studies have established an association between opioid use and risk of falls or fractures in the older population. ${ }^{10-17}$ In a nested case-control study, Moden and colleagues found that using psychotropic drugs increased the risk of falls in older people. Specifically, opioid use was more likely to induce a fall within the next week (odds ratio $[\mathrm{OR}]=6.07$ for men and 5.16 for women). ${ }^{13}$ In another study in a level- 1 trauma centre with patients of all ages, falls were more prevalent among patients who had used opioids in the month preceding the trauma compared with patients who had not (32.8\% v. $22.0 \%) .{ }^{10}$ Furthermore, Söderberg and colleagues found that taking opioids increases the likelihood of an imminent fall-related injury. ${ }^{12}$ For example, having a prescription of opioids filled 1 week before the fall is associated with an OR of 5.14 of falling compared with an OR of 1.23 when the prescription is filled within 4 weeks of the fall. However, other studies did not find a significant association between opioid use and falls, ${ }^{18-20}$ and none examined this in severely injured older people who are at higher risk of death.

The objectives of the study were to examine the association between recent opioid use and the risk, as well as the clinical outcomes, of fall-related injury in a large trauma population of older adults. We hypothesized that fall-related injuries will be more likely to occur with recent opioid use than injuries that occur from other mechanisms. 


\section{Methods}

\section{Study design and population}

We conducted a retrospective, multicentre cohort study using medical consultations and medications from 2 governmental population databases (Quebec Trauma Registry and Régie de l'assurance maladie du Québec [RAMQ]). We included patients aged 65 years and older who were admitted for injury in any of the 57 adult trauma centres ( 3 level I, 5 level II, 21 level III and 28 level IV) in the province of Quebec, Canada, between Jan. 1, 2004, and Mar. 31, 2014. We excluded patients who were not covered by the RAMQ medication insurance for the year preceding the trauma and patients with no recorded mechanism of their injury.

\section{Data sources}

The Quebec Trauma Registry was developed in 1993 and involves the mandatory collection of prospective data for patients admitted to any trauma centre according to the following criteria: deaths following injury, hospital stay greater than 2 days, intensive care unit or transfer from another hospital. Medical archivists extract registry data from patients' medical files using standardized coding protocols. Anatomic injuries are coded with the Abbreviated Injury Scale according to recommendations published by the Association for the Advancement of Automotive Medicine. ${ }^{21}$ The registry is centralized at the RAMQ of the Quebec Ministry of Health and is subject to periodic validation.

The RAMQ medical consultations and medication database is an administrative database maintained by the Quebec Ministry of Health and contains diagnostic information of all medical consultations and medication prescriptions filled for every patient covered by the RAMQ medication insurance in the province of Quebec, which represents $78 \%$ of our sample. The medication database contains the date of dispensation, common drug denominations, form, dosage and quantity prescribed by physicians.

We linked the 2 databases using unique anonymous identification numbers provided by the RAMQ. Patient information was available for the time period ranging from 1 year before the trauma to 8 years after hospital discharge (maximum allowed).

\section{Outcomes}

We searched for filled opioid prescriptions, including codeine, hydromorphone, meperidine, oxycodone, methadone, fentanyl, tramadol, tramacet, pentazocine and morphine. Hydrocodone is not used for pain management in Canada. Recent opioid use was defined as filling at least 1 opioid prescription during the 14 days preceding the target trauma. ${ }^{17}$ Some authors chose a 28- to 30-day period $^{10,12}$ before trauma, but Söderberg and colleagues found a greater association between opioid use and falls with a 2-week period. In a sensitivity analysis, we divided the recent opioid users into 2 groups: those who used opioids in the 2 -week period preceding the trauma but had not filled a prescription for opioids in the previous 3 months (naive opioid user), and those who had used opioids in the 2-week period preceding the trauma and in the previous 3 months (non-naive opioid user).
Variables

From the 2 databases, we extracted the following data: age, sex, injury mechanisms (fall, motor vehicle crash, penetrating injury or blunt object injury), Injury Severity Score (ISS), Abbreviated Injury Scale, number of injuries, duration of stay in emergency department, duration of stay in hospital, surgery during hospital stay and admission to intensive care unit (ICU), as well as history of alcoholism, depression or anxiety 1 year before the target injury. We used an ISS score greater than 15 to define major trauma or polytrauma. ${ }^{22}$ We used the first digit of the Abbreviated Injury Scale score to identify the injury regions for each wound, and the RAMQ medical consultation database to identify patients who had an International Classification of Disease (ICD)-9 or ICD-10 code for depression, anxiety, alcoholism, falls leading to hospital admission, diagnosis of malignant tumour or other comorbidities (asthma, diabetes, high blood pressure, Parkinson disease, chronic airway obstruction, renal failure, heart failure, coronary artery atherosclerosis and dementia) during the year preceding the injury. Finally, we searched in the RAMQ medication database for at least 1 filled prescription of medication known to affect balance according to the Beers Criteria for Potentially Inappropriate Medication Use in Older Adults $^{23}$ (antidepressant, antipsychotic, benzodiazepine, anticholinergic, antithrombotic and cardiovascular drugs) during the 14 days preceding the target trauma.

\section{Statistical analysis}

We compared the characteristics of the included sample and those of patients who were excluded using Cohen's effect sizes. We evaluated associations between mechanism of injury (fall v. other) and recent opioid use and clinical characteristics using univariate and multivariate logistic regression analyses.

In patients who had sustained injuries after a fall, we evaluated associations between opioid prescriptions filled 2 weeks before the fall and trauma outcomes using univariate and multivariate logistic regression analyses. Finally, we used a multivariate logistic regression to estimate the association between inhospital mortality and opioid consumption within 2 weeks before the fall while controlling for confounding factors. Finally, as a sensitivity analysis, we evaluated the association between opioid use (naive or non-naive opioid users) and injury mechanism or in-hospital mortality using multivariate logistic regression analyses. Alpha levels were set at 0.05 and all analyses were performed using SPSS version 23 (IBM, Somers, NY).

\section{Ethics approval}

Access to the administrative database and medication database maintained by the Quebec Ministry of Health required the approval of the ethics review boards of the Commission d'accès à l'information du Québec and of the Responsable de l'accès à l'information et de la protection des renseignements personnels de la RAMQ.

\section{Results}

The Quebec Trauma Registry included a total of 84241 adult patients aged 65 and older who were admitted for a trauma between 2004 and 2014. Of these patients, we excluded 16.5\% because they were not covered by the RAMQ medication insurance 
and another $2.8 \%$ because they did not have a valid code for injury mechanism, leaving 67929 patients for the final sample (Appendix 1, Supplemental Figure S1, available at www.cmaj.ca/ lookup/suppl/doi:10.1503/cmaj.171286/-/DC1). Excluded patients were similar in all aspects to the selected sample (Appendix 2, Supplemental Table S2, available at www.cmaj.ca/ lookup/suppl/doi:10.1503/cmaj.171286/-/DC1).

For the whole sample, the mean age was $81.0( \pm 8.0)$ years and $69 \%$ were female. The most common mechanism of injury was falls (92\%), 59\% had surgery and the median hospital stay duration was 12 days. The percentage of patients who had filled an opioid prescription within 2 weeks preceding any type of injury was $4.6 \%$ (95\% confidence interval $[\mathrm{Cl}] 4.4 \%-5.0 \%)$. This percentage was $4.9 \%(95 \% \mathrm{Cl} 4.7 \%-5.1 \%)$ for patients who had a fall-related injury, and $1.5 \%(95 \% \mathrm{Cl} 1.2 \%-1.8 \%)$ for patients who had an injury via another mechanism. Opioid prescriptions filled before injuries were most frequently hydromorphone (35\%), oxycodone (24\%), morphine (20\%) and fentanyl (14\%).

Table 1 shows the unadjusted and adjusted ORs for patients who had a fall compared with patients who had an injury via another mechanism. Controlling for confounding variables, being older ( $\geq 85 \mathrm{yr}: \mathrm{OR}=5.6 ; 95 \% \mathrm{Cl} 5.1-6.2$ ), being a female $(\mathrm{OR}=2.4 ; 95 \% \mathrm{Cl} 2.3-2.5)$, having filled a prescription of medications known to affect balance (OR $=1.8 ; 95 \% \mathrm{Cl} 1.7-1.9)$, having falls leading to hospital admissions, having a history of alcoholism during the year before target injury, having a history of fractures, receiving a diagnosis of malignant tumour in the year before the injury, having more comorbidities in the year before the injury, and filling an opioid prescription (within 2 weeks before the injury) were all significantly associated with falls.

\begin{tabular}{|c|c|c|c|c|}
\hline Predictors & $\begin{array}{c}\text { Fall, no. }(\%)^{\star} \\
n=62284\end{array}$ & $\begin{array}{c}\text { Other, no. }(\%)^{\star} \dagger \\
\quad n=5645\end{array}$ & $\begin{array}{l}\text { Unadjusted } \\
\text { OR }(95 \% \mathrm{CI})\end{array}$ & $\begin{array}{l}\text { Adjusted } \neq \\
\text { OR }(95 \% \mathrm{Cl})\end{array}$ \\
\hline \multicolumn{5}{|l|}{ Sex } \\
\hline Female & $44108(70.8)$ & $2535(44.9)$ & $2.98(2.82-3.15)$ & $2.40(2.27-2.54)$ \\
\hline Male & $18176(29.9)$ & $3110(55.1)$ & Reference & Reference \\
\hline \multicolumn{5}{|l|}{ Age category, yr } \\
\hline $65-74$ & $14357(23.1)$ & $2823(50.0)$ & Reference & Reference \\
\hline $75-84$ & $25790(41.4)$ & $2205(39.1)$ & $2.30(2.17-2.44)$ & $2.00(1.88-2.13)$ \\
\hline$\geq 85$ & $22137(35.5)$ & 617 (10.9) & $7.06(6.45-7.72)$ & $5.63(5.14-6.16)$ \\
\hline \multicolumn{5}{|l|}{ History of alcoholism } \\
\hline Yes & $750(1.2)$ & $69(1.2)$ & $0.99(0.78-1.26)$ & $1.63(1.26-2.10)$ \\
\hline No & $61534(98.8)$ & $5576(98.8)$ & Reference & Reference \\
\hline \multicolumn{5}{|c|}{ Prescription of medications§ known to affect balance filled 2 wk before injury } \\
\hline Yes & $19111(30.7)$ & $951(16.8)$ & $2.19(2.03-2.35)$ & $1.80(1.67-1.94)$ \\
\hline No & $43173(69.3)$ & $4694(83.2)$ & Reference & Reference \\
\hline \multicolumn{5}{|c|}{ Falls leading to hospital admission in yr before injury } \\
\hline Yes $(\geq 1) \uparrow$ & $1230(2.0)$ & $38(0.7)$ & $2.97(2.15-4.11)$ & $1.77(1.27-2.48)$ \\
\hline No & $61054(98.0)$ & $5607(99.3)$ & Reference & Reference \\
\hline \multicolumn{5}{|l|}{ Fractures in yr before injury } \\
\hline Yes & $4359(7.0)$ & $224(4.0)$ & $1.82(1.59-2.09)$ & $1.38(1.20-1.59)$ \\
\hline No & $57925(93.0)$ & $5421(96.0)$ & Reference & Reference \\
\hline \multicolumn{5}{|c|}{ Diagnosis of malignant tumour in yr before injury } \\
\hline Yes & $8946(14.4)$ & $813(14.4)$ & $1.00(0.92-1.08)$ & $1.10(1.01-1.19)$ \\
\hline No & $53338(85.6)$ & $4832(85.6)$ & Reference & Reference \\
\hline No. of comorbidities, mean \pm SD & $0.77 \pm 0.84$ & $0.68 \pm 0.80$ & $1.14(1.10-1.18)$ & $1.09(1.05-1.13)$ \\
\hline \multicolumn{5}{|c|}{ Opioid prescription filled within $2 \mathrm{wk}$ before injury } \\
\hline Yes & $3041(4.9)$ & $85(1.5)$ & $3.36(2.70-4.17)$ & $2.42(1.94-3.02)$ \\
\hline No & $59243(95.1)$ & $5560(98.5)$ & Reference & Reference \\
\hline \multicolumn{5}{|c|}{$\begin{array}{l}\text { Note: } \mathrm{Cl}=\text { confidence interval, } \mathrm{OR}=\text { odds ratio; } \mathrm{SD}=\text { standard deviation. } \\
\text { *Unless otherwise indicated. } \\
\text { tORs are presented for falls compared with motor vehicle crash and weapons or penetrating injury mechanisms. } \\
\text { tAdjusted for all variables included in this table. } \\
\text { §Antidepressant, antipsychotic, benzodiazepine, anticholinergic, antithrombotic and cardiovascular drugs. } \\
\text { IOnly } 0.2 \% \text { had } 2 \text { or more falls leading to hospital admission in the year before the target injury. }\end{array}$} \\
\hline
\end{tabular}


Notably, patients who had filled an opioid prescription within 2 weeks before injury were 2.4 times $(95 \% \mathrm{Cl} 1.9-3.0)$ more likely to have suffered a fall rather than an injury via another mechanism.

For patients who had suffered a fall-related injury, those who had filled an opioid prescription within 2 weeks before the injury had significantly more thorax and spine regions affected, were more likely to be women and had longer hospital stays (Table 2). There was also an increase in mortality during hospital stay in these patients compared with those who did not use opioids. However, recent opioid use was associated with a decreased number of ICU admissions, a decreased need for surgery, a decreased number of incidents of major trauma (ISS > 15), a decreased number of patients with 3 injuries or more and

\section{Table 2: Associations between opioid use and trauma outcomes in patients who had a fall*}

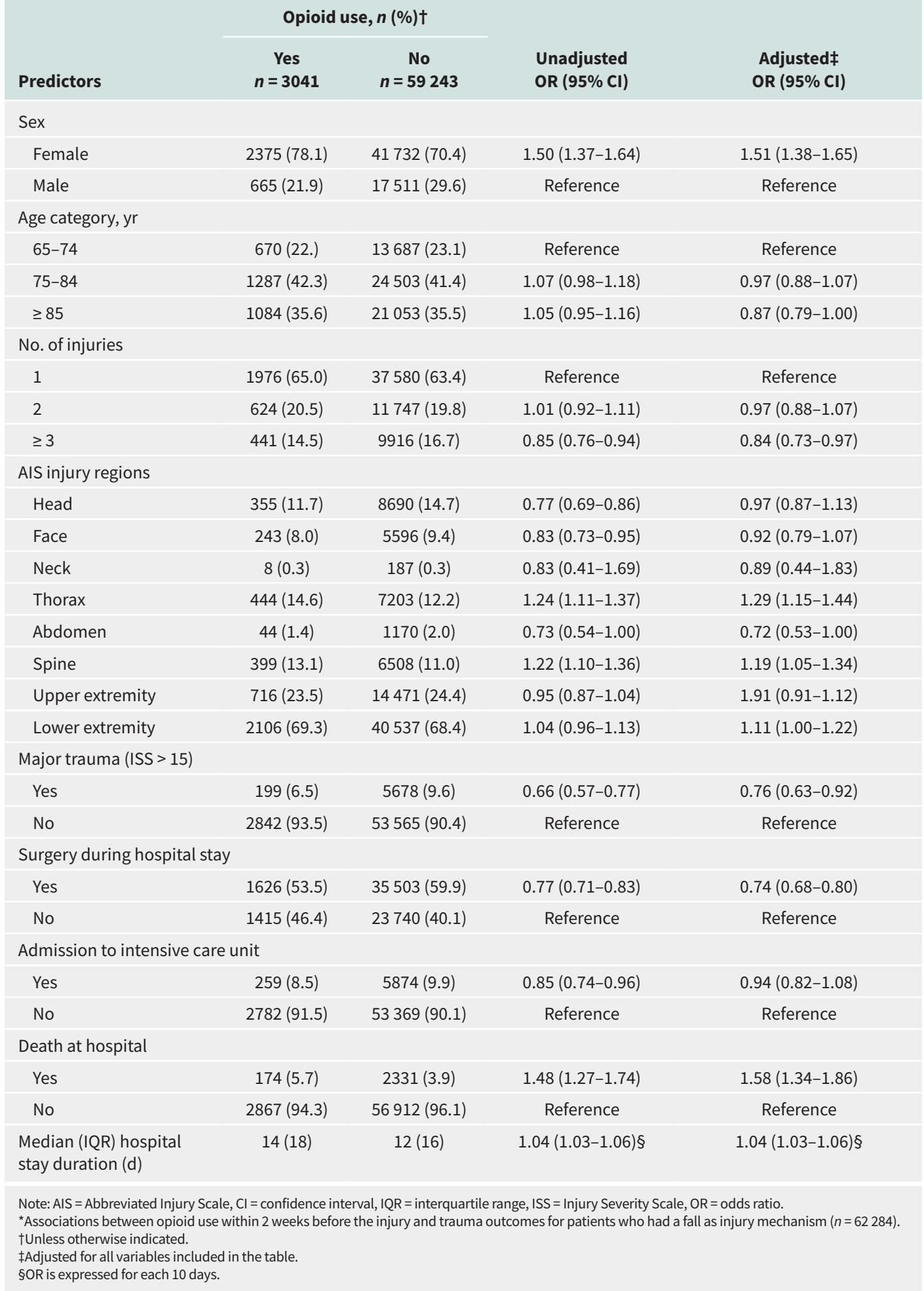


a decreased number of head and face injuries. When controlled for all other variables, the variables of ICU admission and head or face injuries were no longer statistically significant.

Controlling for confounding factors, patients who filled an opioid prescription within 2 weeks before falling were at increased risk $(\mathrm{OR}=1.59 ; 95 \% \mathrm{Cl} 1.35-1.87)$ of death during their hospital stay. Being male, being older, presenting with major trauma, being admitted to the ICU, having multiple comorbidities, having filled a prescription of antipsychotics within 14 days before the injury and having a malignant tumour in the year

\section{Table 3: Predictors associated with death in hospital for patients with fall as the injury mechanism*}

\begin{tabular}{cccc} 
& \multicolumn{2}{c}{ Hospital mortality, no. $(\%) \dagger$} & \\
& Yes & No & Adjusted OR† \\
Predictors & $n=2505$ & $n=59779$ & $(95 \% \mathrm{Cl})$
\end{tabular}

Sex

$\begin{array}{lllc}\text { Male } & 1020(40.7) & 17156(28.7) & 1.58(1.45-1.73) \\ \text { Female } & 1485(59.3) & 42623(71.3) & \text { Reference }\end{array}$

Age category, yr

$\begin{array}{lccc}65-84 & 283(11.3) & 14073(23.5) & \text { Reference } \\ 75-84 & 895(35.7) & 24895(41.6) & 2.05(1.79-2.36) \\ \geq 85 & 1326(52.9) & 20811(34.8) & 4.41(3.83-5.05)\end{array}$

No. of injuries

$1454(58.0) \quad 38102(63.7)$

Reference

2

$474(18.9) \quad 11897(19.9)$

$1.02(0.92-1.14)$

$\geq 3$

$577(23.0) \quad 9780(16.4)$

$1.13(1.01-1.27)$

Major trauma (ISS > 15)

$\begin{array}{lccc}\text { Yes } & 506(20.2) & 5371(9.0) & 1.65(1.46-1.86) \\ \text { No } & 1999(79.8) & 54408(91.0) & \text { Reference }\end{array}$

Admission to intensive care unit

$\begin{array}{lccc}\text { Yes } & 747(29.8) & 5386(9.0) & 4.05(3.67-4.47) \\ \text { No } & 1758(70.2) & 54393(91.0) & \text { Reference }\end{array}$

Diagnosis of malignant tumour in yr before fall

$\begin{array}{lccc}\text { Yes } & 459(18.3) & 8487(14.2) & 1.28(1.15-1.42) \\ \text { No } & 2046(81.7) & 51292(85.8) & \text { Reference }\end{array}$

No. of comorbidities, $\quad 0.86 \pm 0.90 \quad 0.77 \pm 0.83 \quad 1.07(1.03-1.13)$ mean \pm SD

Antidepressant prescription filled within $2 \mathrm{wk}$ before fall

$\begin{array}{cccc}\text { Yes } & 493(19.7) & 11635(19.5) & 0.96(0.86-1.07) \\ \text { No } & 2012(80.3) & 48144(80.5) & \text { Reference }\end{array}$

Antipsychotic prescription filled within 2 wk before fall

$\begin{array}{cccc}\text { Yes } & 306(12.2) & 4731(7.9) & 1.77(1.55-2.01) \\ \text { No } & 2199(87.8) & 55048(92.1) & \text { Reference }\end{array}$

Benzodiazepine prescription filled within $2 \mathrm{wk}$ before fall

$\begin{array}{cccc}\text { Yes } & 57(2.3) & 1577(2.6) & 0.89(0.68-1.17) \\ \text { No } & 2448(97.7) & 58202(97.4) & \text { Reference }\end{array}$

Opioid prescription filled within 2 wk before fall

$\begin{array}{cccc}\text { Yes } & 174(6.9) & 2867(4.8) & 1.59(1.35-1.87) \\ \text { No } & 2331(93.1) & 56912(95.2) & \text { Reference }\end{array}$

Note: $\mathrm{Cl}=$ confidence interval, ISS = Injury Severity Scale, $\mathrm{OR}=$ odds ratio, $\mathrm{SD}=$ standard deviation .

*Patients who had a fall as injury mechanism: $n=62284$.

†Unless otherwise indicated.

$\ddagger$ Adjusted for all variables included in the table. 
before the fall were also significantly associated with in-hospital mortality (Table 3).

In a sensitivity analysis, naive (adjusted OR $=2.25 ; 95 \% \mathrm{Cl}$ 1.61-3.15) and non-naive (adjusted OR $=4.17$; 95\% Cl 3.14-5.54) opioid users had an increased risk of falls compared with another mechanism of injury. There was also an increase in mortality during hospital stay in naive (adjusted $\mathrm{OR}=1.70 ; 95 \% \mathrm{Cl} 1.28-2.27$ ) and non-naive (adjusted $\mathrm{OR}=1.54 ; 95 \% \mathrm{Cl} 1.27-1.87$ ) opioid users compared with those who did not use opioids.

\section{Interpretation}

This study confirms an association between recent opioid use and fall-related injury in a large trauma population of older adults (67 929 patients). Furthermore, it shows that pre-injury opioid use is also associated with increased hospital mortality for older patients with a fall-related injury. Patients included in the registry had a median hospital stay of 14 days and had to undergo surgery in more than $50 \%$ of cases, suggesting that these injuries had serious consequences. Results were similar for opioid-naive or non-opioid-naive older trauma patients.

Concordant with our results, opioid use has been previously associated with increased risk of fall-related injury. ${ }^{10-14,16,17}$ Our OR of 2.4 (when adjusted for confounders) is comparable with that observed in other studies based on older populations: hazard ratio (HR) of 2.05 in hip fractures, ${ }^{17}$ OR of 3.3 for fall or fracture, ${ }^{11} \mathrm{HR}$ of 2.27 for injury with codeine combination, ${ }^{16}$ and HR of 4.9 for any fractures. ${ }^{14}$ Adverse effects, like the sedation and dizziness frequently observed with opioids, ${ }^{24}$ can compromise coordination and be responsible for fall-related injuries, especially in the older population with increased visual impairment and loss of balance. ${ }^{13}$ In addition to previous opioid use, being a female, being older, having a history of alcoholism and using antidepressants or antipsychotics drugs were significantly associated with fall-related injuries, which is in accordance with previous studies. ${ }^{13,15,25-27}$

We found that more women than men had filled an opioid prescription before the fall-related injury. Another study found the same result but for all types of injury mechanisms. This suggests that women could be more susceptible to the adverse effects of opioids. ${ }^{10}$ There was also a significant but weak association between opioid use before the trauma and back or thoracic injury. This could suggest that older patients who are taking opioids are less inclined to slow down their fall with their arms.

Patients with fall-related injury and recently filled opioid prescriptions had less major trauma, fewer surgeries and fewer concurrent injuries than patients who did not use opioids before the fall, suggesting that their injuries were potentially less severe. However, their median hospital stay was longer and they died more often during the hospital stay, suggesting that a fall associated with opioid use may be a marker of frailty. The only other study that examines mortality with opioid use in trauma patients found no significant relation between the two. ${ }^{10}$ However, the mean age of that sample was younger (42 yr) and included all types of injury mechanisms. It is possible that older patients could be more vulnerable to opioid use than younger patients and, as stated before, it is likely that a fall associated with opioid use is a marker of frailty.
Because these results were not the primary outcome of the present study, they should be confirmed by future studies.

\section{Limitations}

This study has some limitations. The retrospective design of the study can demonstrate only an association between opioid use and falls; no causal relationship between the two phenomena can be inferred. We can hypothesize that because patients generally use opioids to treat pain, it may be the pain itself (and not the opioid) that causes the fall. Furthermore, our definition of opioid use is filling an opioid prescription in the previous 2 weeks, and it is possible that the drug was not consumed by the patient. However, this is also true for patients with other mechanisms of injury. Medications administered during the target hospital stay were not available and therefore could not be controlled in the mortality analysis. In addition, our fall-related injury group was compared with a group of older patients who had other mechanisms of injury (motor vehicle crash or penetrating trauma). These latter patients could have some characteristics that differed from a group of older patients who did not have injury. However, opioids can also affect the attention and reaction time of drivers, so opioid use could also have been a factor for patients who had motor crashes. ${ }^{28}$ Consequently, our association between opioid use and falls could have been higher. Furthermore, we studied only falls that were related to substantial injuries and led to a hospital stay, so the frequency of fall associated with opioids could be higher. Examining only falls related to substantial injuries could also explain the association that we found between opioids and increased in-hospital mortality. Finally, as stated earlier, falls associated with opioid use could be a marker of frailty and not necessarily point to a causal association.

Physicians should be aware that prescribing opioids to older adults is not only associated with an increased risk of falls but also, if these patients do fall, a higher in-hospital mortality rate.

\section{Conclusion}

These results show that recent opioid use is associated with an increased risk of falls in older adults and an increased likelihood of death in those with fall-related injuries.

\section{References}

1. Mazer-Amirshahi M, Mullins PM, Rasooly I, et al. Rising opioid prescribing in adult U.S. emergency department visits: 2001-2010. Acad Emerg Med 2014;21:236-43.

2. Pletcher MJ, Kertesz SG, Kohn MA, et al. Trends in opioid prescribing by race/ ethnicity for patients seeking care in US emergency departments. JAMA 2008; 299:70-8.

3. Volkow ND, McLellan TA, Cotto JH, et al. Characteristics of opioid prescriptions in 2009. JAMA 2011;305:1299-301.

4. Makris UE, Abrams RC, Gurland B, et al. Management of persistent pain in the older patient: a clinical review. JAMA 2014;312:825-36.

5. Chau DL, Walker V, Pai L, et al. Opiates and elderly: use and side effects. Clin Inter Aging 2008;3:273-8.

6. Daoust R, Paquet J, Lavigne G, et al. Impact of age, sex and route of administration on adverse events after opioid treatment in the emergency department: a retrospective study. Pain Res Manag 2015;20:23-8.

7. Hartikainen S, Lönnroos E, Louhivuori K. Medication as a risk factor for falls: critical systematic review. J Gerontol A Biol Sci Med Sci 2007;62:1172-81.

8. Yoshida S. A global report on falls prevention: epidemiology of falls. Geneva: World Health Organisation; 2007. 
9. Huang AR, Mallet L, Rochefort CM, et al. Medication-related falls in the elderly: causative factors and preventive strategies. Drugs Aging 2012;29:359-76.

10. Pandya U, O'Mara MS, Wilson W, et al. Impact of preexisting opioid use on injury mechanism, type, and outcome. J Surg Res 2015;198:7-12.

11. Rolita L, Spegman A, Tang X, et al. Greater number of narcotic analgesic prescriptions for osteoarthritis is associated with falls and fractures in elderly adults. J Am Geriatr Soc 2013;61:335-40.

12. Söderberg KC, Laflamme L, Möller J. Newly initiated opioid treatment and the risk of fall-related injuries. A nationwide, register-based, case-crossover study in Sweden. CNS Drugs 2013;27:155-61.

13. Modén B, Merlo J, Ohlsson H, et al. Psychotropic drugs and falling accidents among the elderly: a nested case control study in the whole population of Scania, Sweden. J Epidemiol Community Health 2010;64:440-6.

14. Miller M, Stürmer T, Azrael D, et al. Opioid analgesics and the risk of fractures in older adults with arthritis. J Am Geriatr Soc 2011;59:430-8.

15. Nurminen J, Puustinen J, Piirtola M, et al. Opioids, antiepileptic and anticholinergic drugs and the risk of fractures in patients 65 years of age and older: a prospective population-based study. Age Ageing 2013;42:318-24.

16. Buckeridge D, Huang A, Hanley J, et al. Risk of injury associated with opioid use in older adults. J Am Geriatr Soc 2010;58:1664-70.

17. Kamal-Bahl SJ, Stuart BC, Beers MH. Propoxyphene use and risk for hip fractures in older adults. Am J Geriatr Pharmacother 2006;4:219-26.

18. Krebs EE, Paudel M, Taylor BC, et al. Association of opioids with falls, fractures, and physical performance among older men with persistent musculoskeletal pain. J Gen Intern Med 2016;31:463-9.
19. Woolcott JC, Richardson KJ, Wiens MO, et al. Meta-analysis of the impact of 9 medication classes on falls in elderly persons. Arch Intern Med 2009;169:1952-60.

20. Blalock SJ, Casteel C, Roth MT, et al. Impact of enhanced pharmacologic care on the prevention of falls: a randomized controlled trial. Am J Geriatr Pharmacother 2010;8:428-40.

21. Abbreviated Injury Scale. Chicago: Association for the Advancement of Automotive Medicine (AAAM) Publications; 1990.

22. Copes WS, Champion HR, Sacco WJ, et al. The Injury Severity Score revisited. J Trauma 1988;28:69-77.

23. American Geriatrics Society 2012 Beers Criteria Update Expert Panel. American Geriatrics Society updated Beers Criteria for potentially inappropriate medication use in older adults. J Am Geriatr Soc 2012;60:616-31.

24. Kalso E, Edwards JE, Moore RA, et al. Opioids in chronic non-cancer pain: systematic review of efficacy and safety. Pain 2004;112:372-80.

25. Campbell AJ, Spears GF, Borrie MJ. Examination by logistic regression modelling of the variables which increase the relative risk of elderly women falling compared to elderly men. J Clin Epidemiol 1990;43:1415-20.

26. Robbins AS, Rubenstein LZ, Josephson KR, et al. Predictors of falls among elderly people. Results of two population-based studies. Arch Intern Med 1989;149:1628-33.

27. Lawlor DA, Patel R, Ebrahim S. Association between falls in elderly women and chronic diseases and drug use: cross sectional study. BMJ 2003;327:712-7.

28. Gomes T, Redelmeier DA, Juurlink DN, et al. Opioid dose and risk of road trauma in Canada: a population-based study. JAMA Intern Med 2013;173: 196-201.
Competing interests: Aline Boulanger reports receiving conference and advisor committee fees from Purdue Pharma and AstraZeneca, advisor committee fees from Paladin, and conference fees from Cannimed and Tilray, outside the submitted work. No other competing interests were declared.

This article has been peer reviewed.

Affiliations: Department of Emergency Medicine (Daoust, Paquet, Chauny), Research Centre, Hôpital du Sacré-Coeur de Montréal; Faculté de Médecine (Daoust, Mac-Thiong, Chauny), Université de Montréal; Montréal, Que.; Département de médecine sociale et préventive (Moore), Faculté de médecine, Université Laval; Axe de recherche en traumatologie-urgence-soins intensifs du Centre de recherche FRQS du CHU-Québec (Moore); Département de médecine familiale et de médecine d'urgence (Émond), Faculté de médecine, Université Laval, Québec, Que.; Department of Emergency Medicine (Gosselin), McGill University Health Centre, McGill University; Faculties of Dental Medicine and Medicine (Lavigne), Université de Montréal; Center for Advanced Research in Sleep Medicine (Lavigne), Hôpital du Sacré-Coeur de Montréal (CIUSSS du Nord de-l'île-deMontréal); Centre de recherche du Centre Hospitalier de l'Université de Montréal (CRCHUM) (Choinière, Boulanger); Département d'anesthésiologie (Choinière), Faculté de médecine, Université de Montréal; Research Centre (Daoust, Paquet, Mac-Thiong, Chauny), Hôpital du Sacré-Coeur (CIUSSS du Nord del'île-de-Montréal), Montréal, Que.

Contributors: Raoul Daoust conceptualized, designed the study and obtained funding. Jean Paquet and Lynne Moore carried out data management and supervised the statis- tical analysis. Raoul Daoust drafted the manuscript and all the remaining authors contributed substantially to its revision. All authors approved the final manuscript as submitted and agree to be accountable for all aspects of the work. All coauthors have read and agree with the manuscript's contents.

Funding: This study was supported by a grant from the Fonds de recherche des urgentistes de l'Hôpital du Sacré-Cœur de Montréal and the Fonds de recherche du Québec - Santé (FRQS) Canada.

Acknowledgements: The authors would like to thank Dominique Petit, Justine Lessard and Martin Marquis for their contributions to the revision of the manuscript.

Accepted: Feb. 14, 2018

Correspondence to: Raoul Daoust, raoul.daoust@videotron.ca 